\title{
Literatura e historia en la creación literaria peruana
}

Por Luis Enrique Tord 
Doctor en Antropología por la Universidad Nacional Mayor de San Marcos. Miembro de la comisión Consultiva de Cultura del Ministerio de Relaciones Exteriores. Miembro de número del Instituto Ricardo Palma 
"Poned este libro aparte [la traducción de Garcilaso Inca de la Vega de los tres Diálogos de Amor de León Hebreo] y recordádmelo cuando, con más tiempo, estemos en El Escorial. Apuntadlo, que no lo olvidéis. Mirad que es fruta nueva del Perú”.

El Rey Felipe II a su secretario.

En este texto, que es parte inicial de una obra de más largo aliento, indago en las relaciones entre literatura e historia en los cronistas del Perú, y de allí en adelante en quienes han frecuentado estas dos esferas creando una literatura singular Pedro de Peralta y Barnuevo, Manuel Ascencio Segura, Manuel Aguirre Morales, Mario Vargas Llosa, entre otros-, de los cuales destaca nuestro don Ricardo Palma de manera considerable.

Es por ello que, entre los cronistas e historiadores virreinales, he comenzado por el insigne Garcilaso Inca de la Vega, cuyas obras histórico-literarias, principalmente La Florida del Inca (1605) y los Comentarios Reales (1609 y 1617), alcanzan la cima de este género entre finales del siglo XVI y principios del XVII. Por cierto que en este recorrido exegético del gran cuzqueño nos ha acompañado las enseñanzas de garcilasistas ilustres, entre quienes es obligatorio mencionar a José de la Riva-Agüero y Osma, Raúl Porras Barrenechea, Aurelio Miró Quesada Sosa y José Durand Flores, por recordar a algunos de los más eminentes. 
Rescato así un texto que escribí en $1987^{1}$, que, revisado hoy, es parte sustantiva de las primeras páginas de este ensayo en preparación. Por cierto que en este período de tiempo han aparecido importantes títulos que revisan el tema de la relación entre literatura e historia en Hispanoamérica lo cual ha enriquecido considerablemente su estudio.

Como se podrá apreciar, estas aproximaciones iniciales que acoge esta respetada revista del Instituto Ricardo Palma, pretenden comprender las diversas corrientes de idas que confluyeron en la atmósfera renacentista en que se desenvolvió el pensamiento del Inca Garcilaso en Andalucía y la gravitación de la forma e intención literaria, y aun simbólica, de su obra.

El neoplatonismo del Inca Garcilaso encontró un espléndido cauce de realización en su monumental historia de los Incas, excepcional esfuerzo intelectual en el que, en sutil trama, se entremezclan el mito y la historia, la poesía y la realidad en el marco grandioso de una sucesión de eras que encuentran coherente fluir en una escala de perfeccionamiento que va desde el caos de una humanidad primitiva hasta una alta civilización, el Tahuantinsuyo, que en todo fue igual o superior a las civilizaciones clásicas, salvo en el conocimiento de la Revelación cristiana. De esta manera, a la historia de grandes reyes y emperadores incas vino a sumarse como en una especie de legítima sucesión monárquica el linaje de los Habsburgo que prosiguieron la labor civilizadora de los antepasados de Garcilaso al expandir en el Nuevo Mundo los fundamentales beneficios de la Fe, y no en menor grado -para un intelectual tan enterado como el Inca- las herencias del mundo antiguo.

1 En Homenaje a Aurelio Miró Quesada Sosa. Vol. 11. pp. 849-857. Talleres Gráficos P. L. Villanueva S. A. Editores. Lima, 1987. 
Su cuidadosa traducción de un texto renacentista esencial como es Diálogos de Amor (1590) de León Hebreo, evidencia la pasión con la que siguió los planteamientos neoplatónicos que desde la segunda mitad del siglo XV fueron decisivos en la formación de los más cultivados espíritus del Viejo Mundo. Garcilaso vivió pues en esta atmósfera y, a no dudarlo, la traducción de Hebreo fue un considerable ejercicio de erudición que lo situó entre los más respetados escritores de formación humanista de la Andalucía del último tercio del siglo XVI y principios del XVII.

Es posible que en sus Comentarios Reales de los Incas (1609-1617) encontremos escasas citas directas de textos clásicos pero sí es inocultable la atmósfera en la que nace y se difunde esta obra que se perfila como un fresco impresionista, entre el resplandor vaporoso de la luz neoplatónica y los personajes, monumentos y paisajes que no llegan a ser del todo convincentes para el lector científico, pues esta obra no fue escrita por un historiador en el sentido actual de esta acepción, sino por un humanista que veía en la narración de los hechos de los Incas un soporte, en la realidad del pasado, a esa su tendencia profunda que lo inducía a buscar los orígenes ejemplares de una sociedad que había llegado a tan elevados estudios civilizadores. A ella se sumó la distancia de tres décadas que mediaba entre su salida definitiva y sin retorno del Cuzco (1560) y los relatos idealizadores que escuchó en el regazo de su madre la palla Isabel Chimpu Ocllo, así como los de sus ancianos parientes indígenas que habían vivido el esplendor imperial hasta su extinción con la conquista ibérica.

Cómo está tan imbricado el neoplatonismo en su obra histórica lo demuestra también el hecho de que ya había iniciado su vocación en esta última disciplina al propio tiempo que concluía la traducción de los Diálogos tal como lo asevera en su carta a don Maximiliano de Austria -del 12 de marzo de 1587- en la que afirma que "está ya escrita más de la cuarta parte" de la 
Historia de la Florida (1605).

He leído detenidamente, una vez más, los Diálogos de Amor de Jehudah Abarbanel -más conocido como León Hebreo- en la espléndida traducción del Inca. Y en esta oportunidad ya no me resisto a escribir esta ofrenda personal a ese cuzqueño ilustre y tan poco, comprendido en un aspecto decisivo de su vida intelectual: sus hondas convicciones neoplatónicas.

Entiendo que las grandes distancias que nos separan hoy de la irradiación del Renacimiento así como de su cultura humanista, inentendible sin un correcto conocimiento del pensamiento clásico y la herencia intelectual bizantina, explica la indiferencia - por no decir desconocimiento- acerca de las profundas corrientes espirituales que impregnaron el cenáculo de amigos de Garcilaso y las convicciones que animaron su concepción filosófica del mundo. Concepción que está en la base de su obra histórica al punto de que soslayarla hace equivocado, errático e impreciso cualquier juicio sobre ella.

De los múltiples aspectos que pueden tocarse hay uno que siempre me inquietó sobremanera: su concepción cíclica del tiempo. El que Garcilaso haya considerado, o creído, en un desenvolvimiento del universo constituido por ciclos, por períodos previsibles fatalmente incluidos en su evolución, nos revelaría varias cosas: su serenidad para comprender dramas de tanta envergadura como el final del Imperio de los Incas, sus mayores; los conocimientos que tuvo de que también en el pensamiento aborigen cuzqueño se conservó la tradición de una sucesión de eras cuya versión fue recogida por diversos cronistas, pero él cuidadosamente soslayó a propósito; y su proximidad a una de las ideas sustantivas del pensamiento neoplatónico -la de los ciclos- que con tanto detalle describe León Hebreo en una de las partes más notables de su célebre tratado. 
La idea de que el acontecer universal se ajusta a una sucesión de revoluciones preestablecidas se explica en aquellos párrafos de su traducción de los Diálogos en que los protagonistas, Sofía y Filón, conversan acerca del tiempo de duración del mundo. Sobre estos cálculos Filón asevera que los "teólogos, más antiguos que Platón, de los cuales él fue discípulo, dicen que el mundo inferior se corrompe y renueva en siete mil años". Y aclara que de estos siete mil años, "los seis mil están siempre brotando el caos de los inferiores cuerpos, y acabados estos, dicen que, recogiendo en sí toda cosa, se reposa en el siete milésimo año; en aquel espacio de tiempo conocible para nueva generación, para otros seis mil años". Siguiendo con esos cálculos pasa del mundo inferior a la totalidad del cielo afirmando que "corrompido el mundo inferior siete veces, de siete mil años en siete mil años viene a divolverse el cielo, con todo él lleno; y toda cosa vuelve al caos y a la materia primera. Y esto viene a ser una vez después de pasados cuarenta y nueve mil años". Pero este volver al caos primordial, "torna a preñarse de la divinidad y a brotar el mundo y a formarse otra vez".

No menos singular resulta la afirmación astrológica de esta propuesta cuando Hebreo asevera que la octava es la era "donde está la multitud de las estrellas" y demora en su circulación 49.000 años. Tal como lo afirma Filón, “según ellos [los astrólogos] nada más que el tiempo de una sola revolución de la octava esfera dura toda la vida suya y el resto del universo". De esta forma explican estos teólogos que "tanta es la vida del mundo cuanto la octava esfera está en dar una vuelta, y, acabada ésta, se disuelve con todo el resto, volviéndose las formas a la divinidad y las materias a la madre caos, el cual, haviendo reposado mil años, vuelve a concebir del entendimiento divino, e, informado otra vez de todas sus ideas, después de cincuenta mil años, vuelve a brotar el cielo y la tierra y las otras cosas del universo. Y los astrólogos, notando esto, dicen 
que, dando la octava esfera una vuelta, se vuelven todas las cosas como al principio". En resumidas cuentas, concluye Filón, que "aviendo declinado las esencias criadas de grado en grado, no solamente hasta el último orbe de la Luna mas también hasta la íntima materia primera, desde allí buelve a levantarse la materia primera con inclinación, amor y deseo de acercarse a la perfección divina... Desta suerte hazen los árabes una línea circular del universo, cuyo principio es la divinidad. . .”.

¿No encontraría Garcilaso irresistiblemente sugestivas estos cálculos y su vinculación con los Incas? ¿Y no le recordarían las convicciones de transtornos previsibles en los que también creían los Incas de acuerdo a sus oráculos y vaticinios? Respecto de la conquista del Tahuantinsuyo no puede habérsele ocultado a Garcilaso la advertencia de que, concluyendo su traducción en el año de 1586, y habiendo cumplido esta era 5.300 años al momento de la conquista del Tahuantinsuyo (1533), esta cifra coincidía con un pachacuti de medio milenio. Quinientos años que, a su vez, abría otro ciclo de un milenio en los Andes -hasta el 2.033- fecha que concordaba con los seis mil años a partir de los cuales se recogerá “en sí toda cosa”, según el pronóstico neoplatónico cabalístico de Jehudah Abarbanel.

Otro escritor coetáneo de Garcilaso que recorría por esos años el extenso Virreinato del Perú, Felipe Guamán Poma de Ayala, trataba también en su Nueva corónica y buen gobierno (1615) acerca de que en la visión andina del mundo se concebía la existencia de cinco edades. No se nos escapa que esta versión de un cronista indio que estuvo tan vinculado a los jesuitas y a los extirpadores de idolatrías, recuerda, en su concepción y cifras, planteamientos de cabalistas europeos ${ }^{2}$. Estas eras o

2 Recordemos que inclusive pudo circular una versión presumiblemente en quechua de los Diálogos de Amor si nos atenemos a la aseveración del Inca 
"soles" milenarios fueron tratados también por otros cronistas que, evidentemente, tuvieron inquietudes en campos del conocimiento afines a los de León Hebreo y a los de Garcilaso, como el jesuita Blas Valera-cuyo manuscrito sobre el Perú tuvo en sus manos el historiador cuzqueño-, el fraile mercedario Martín de Murúa, el franciscano Buenaventura de Salinas y personaje tan singular como el licenciado Fernando de Montesinos. Todos ellos recogieron en ciertas tradiciones andinas la explicación de las eras milenarias -las intiphuapan o capachuatan- que evocaban interpretaciones cosmológicas expuestas en libros de tanta gravitación en el pensamiento humanista español como Diálogos de Amor. Diálogos que no han leído con detenimiento o que sencillamente no han leído quienes pretenden comprender el pensamiento andino de los siglos XVI y XVII. Diálogos a los que se aplicó la censura del Santo Oficio precisamente en los párrafos de los cálculos proféticos milenaristas que tradujo con tanto cuidado y elegancia Garcilaso... y de los que a su manera trataran en el Nuevo Mundo, con particular detalle, los historiadores mencionados. Con tal detalle e interés que sin el tema de las edades o "soles" -verdadera piedra angular de sus pensamientos- las Memorias Antiguas Historiales y Politicas del Perú (c. 1640) de Fernando de Montesinos carecerían en absoluto de sentido.

Entendemos que Garcilaso no hiciera referencia alguna al tema de los ciclos en sus Comentarios Reales de los Incas pues temió un nuevo conflicto con la Santa Inquisición que habría encontrado sospechosas o condenables estas disquisiciones tan enfrentadas

Garcilaso en el prólogo de la Segunda Parte de los Comentarios Reales de los Incas cuando dice: "También por aprovechar los años de mi edad y servir a los estudiosos traduje de italiano en romance castellano los Diálogos de filosofía entre Filón y Sofía, libro intitulado: León Hebreo, que anda traducido en todas las lenguas hasta en lenguaje peruano (para que se vea a do llega la curiosidad y estudiosidad de los nuestros)". 
con la doctrina cristiana. Precisamente este asunto era el que había ocasionado la inclusión de su traducción de los Diálogos de Amor en el Index librorum prohibitorum y no iba a exponerse otra vez, en obra de la envergadura de la historia de los Incas, y en su calidad de clérigo de órdenes menores, a una renovada objeción del Tribunal del Santo Oficio. Es por ello que sus alusiones a eras previsibles en el acontecer andino las veía bajo otras formas como aquellas en las que alude un oráculo que profetizaba que la dinastía de los Incas concluiría cuando "pasados tantos reyes, habían de ir gentes extrañas y nunca vistas y quitarles el reino". O aquel de la caída de un águila real perseguida por halcones y cernícalos en el Huacaipata, la Plaza Mayor del Cuzco, interpretado como vaticinio de la caída del Imperio; o el de la luna rodeada de tres cercos que anunciaban la destrucción del Tahuantinsuyo.

Este tema debió ser crucial en Garcilaso. Tan crucial que se prohíbe expresamente en el Novus Index (1632) el párrafo de los Diálogos referente al retorno del universo cada siete mil años al caos primitivo. Ya el propio Garcilaso había aludido a la prohibición de su traducción de los Diálogos por la Inquisición en el Index de 1612 en su prólogo a la Segunda Parte de los Comentarios Reales donde dice que el Santo Oficio la "mandó recoger en la nuestra lengua vulgar, porque no era para vulgo". Sin embargo hay que precisar que el Santo Oficio, en rigor, no la recogió sino que este Tribunal se circunscribió a clasificarla en la segunda categoría de obras prohibidas y, por lo tanto, pudo circular con la restricción señalada, es decir, con la obligación de transcribirse el mandato de expurgación en lugar destacado.

Es comprensible entonces que Garcilaso sufriera una dolorosa tensión entre su profundo amor por el divino ateniense, autor de aquellos otros Diálogos famosos, y su pertenencia a una sociedad vigilada por la susceptibilidad de la Iglesia y del Santo Oficio. Es 
ciertamente inocultable su filiación doctrinaria cuando, a pesar de esas negativas circunstancias tradujo y publicó esa obra de León Hebreo, flor del pensamiento neoplatónico, que roza o se hunde en definitiva en tradiciones por demás apartadas de la ortodoxia cristiana.

Garcilaso opta entonces por trasladar su neoplatonismo a la reconstrucción de un pasado -el del Imperio de los Incas- del que no solo se sentía orgulloso por los contundentes argumentos de la sangre, sino porque se intuyó predestinado a legar a la posteridad una versión única, integral, ordenada y, ¿ipor qué no decirlo?, espiritual, ejemplar, de esa sociedad admirable por muchos conceptos. Y, en ese sentido, su pretensión no fue solo escribir una historia, o la historia de los Incas. No. Su pretensión esencial, como que era un poeta platónico, fue proyectar al futuro una imagen profunda del interior de ese imperio. El sabía que la historia se puede escribir de muchas formas. Y no quiso escribir una historia más. Garcilaso pretendió, y lo consiguió, mediante un esfuerzo intelectual excepcional, encerrar como en una esfera mágica, suficiente en sí misma, la narración de la vida, creencias, pensamientos y hechos de una espléndida utopía real. Una utopía mucho más convincente que la de su más ilustre antecedente inmediato: Utopía (1516) de Tomás Moro. Este ilustre escritor neoplatónico y los que le siguieron más tarde -Campanella y Bacon- describieron sociedades ideales que fueron producto de sus fantasías. En otros términos, eran fantasía. Fueron brillantes ensayistas que decidieron soñar despiertos, inventando sociedades que existían solo en su imaginación. En cambio la obra magna del Inca Garcilaso es la creación de una utopía forjada con el aliento y la sangre de una realidad.

Garcilaso sueña una realidad mientras Moro (y Campanella y Bacon) sueña un sueño. 
El Inca tuvo la genialidad de escribir acerca de una sociedad que a través de su obra suscitó la admiración y el respeto del Viejo Mundo. Y en ello andaba implícita una sutil e incisiva crítica a la Europa de su tiempo. Su utopía real fue tan poderosa que propuso una imagen ideal de la que sus ancestros habían logrado hasta el extremo de que muchos pretendieron estar entroncados con la sangre real de los Incas, pretensión que inclusive estuvo en la base de las reivindicaciones andinas que acaudilló en 1780 José Gabriel Condorcanqui, Tupac Amaru II. El propio Simón Bolívar llevaba en su morral de guerrero los Comentarios Reales que debieron alimentar, más de lo que se supone, su visión y conocimiento del mundo clásico andino del que estaba tan remoto por su procedencia cultural atlántico caribeña. ¿Y acaso no gravitó Garcilaso en Francisco de Miranda que soñaba en un estado americano libre con un Inca por Rey? ¿0 en la poderosa corriente independentista platense que previó una solución similar para las futuras naciones emancipadas? El formidable neoplatonismo de Garcilaso ha seguido transmitiéndose hasta el Perú contemporáneo atravesando durante décadas el espinazo de las ideologías más diversas. De esta manera las propuestas doctrinarias políticas más eficaces de los últimos lustros han estado inspiradas implícitamente en el mensaje garcilasista que le da grandeza, altura y raíz -desde el fondo del tiempo- a toda sugerencia que movilice al mundo andino hacia metas propias.

Me he preguntado repetidas veces si en el esfuerzo de los historiadores, en particular de los que buscan tenazmente la existencia de leyes que gobiernan los acontecimientos humanos, no hay como un soterrado, persistente y hasta desesperado deseo de cercar el caos, de ponerles compuertas a esas poderosas corrientes adversas de la destrucción y la muerte que parecieran amenazar el precario Orden de las vidas individuales y colectivas. En los neoplatónicos, a más de haber sido la historia un género literario -y por lo tanto una posibilidad más para ejercer el 
dominio de la forma- fue también una manera de comprender en grandes magnitudes la realización de un proyecto divino, providencial, y aproximarse así, por otros senderos, a las leyes que encarnan en la vida expresando en ello el esplendor de la inteligencia, la belleza, el valor, la grandeza. El mismo drama de la vida es rescatado de la amenaza del sinsentido y colocado en una perspectiva que puede ser gloriosa u oscura, soberbia, o humilde, pero preñada de dirección, de auténtico protagonismo en la gran trama cosmogónica universal.

Por todo ello entiendo que el Inca al escribir sus Comentarios Reales lo hiciera arrebatado por la convicción de que la historia de un pueblo civilizador supone la del despliegue de una acción ordenadora. De una acción que una elite emprende como parte sustancial de un designio divino al extremo de asumir su destino como colaboradora terrena de los vastos y sagrados proyectos de la Providencia.

Pudo pues el linaje de los Incas no conocer la verdad revelada por el Hijo de Dios, así como los grandes del mundo clásico -incluidos Platón y Aristóteles- no la conocieron, pero todos tuvieron un anticipo de ello en el preclaro conocimiento de la verdad natural. Esta idea es esencial para comprender el amoroso deleite de Garcilaso en el neoplatonismo que dejaba espacio tan vasto para que los gentiles llegaran a la sabiduría poética, filosófica o política a pesar de su desconocimiento de la religión verdadera. Más aún, el audaz pensamiento humanista del cuzqueño llegó hasta el punto de sugerir implícitamente en su historia de los Incas que la moral y los conocimientos, inclusive teológicos que llegaron a alcanzar, fueron un providencial anticipo del mensaje salvador de los Evangelios.

Si bien no lo dice (no podía decirlo) está subyacente en su magna empresa histórica de los Comentarios Reales la sugerente 
demostración de cómo el Imperio de los Incas se aproximó en mucho a las utopías que tanta audiencia tuvieron en el Renacimiento y que derivaron del ilustre antecedente de $L a$ República de Platón. El genio de Garcilaso residió pues en haber impregnado el espíritu, el sutil sentido de la historia, de un aliento épico del más alto abolengo en el que sin aseverarlo explícitamente demostró cómo el Tahuantinsuyo fue gobernado por una aristocracia insigne por su eminente capacidad política, su eficacia administradora, sus grandes cualidades guerrera, su justicia distributiva y, por encima de todo, su excepcional maestría para organizar en el inmenso territorio del Tahuantinsuyo un imperio que agrupaba a muy diversas sociedades regidas por la voluntad ordenadora que había presidido el destino de los reyes incas desde la aparición de los fundadores del linaje -Manco Cápac y Mama Ocllo-, la mítica pareja civilizadora.

Inclusive el dios supremo, padre de aquellos reyes andinos, el Sol, tiene en Garcilaso un aspecto benévolo, constructor, positivo. Y no digamos nada de otras divinidades que ni siquiera eran representadas por imágenes como Illia Ticci Viracocha o Pachacamac. Es decir, divinidades tan inasibles como el propio Dios del cristianismo.

Pero esta tendencia a la utopía generó una reacción paradójica y contradictoria por cuanto la invasión ibérica, en la que había participado su padre, Sebastián Garcilaso de la Vega, aparece como la inserción del caos en esa república idílica. Un caos que a duras penas logró el Inca justificar con el beneficio de la predicación de la Fe católica. Pero aquí debió funcionar, aunque no lo quisiera decir -una vez más por su experiencia adversa con el Tribunal del Santo Oficio de la Inquisición- ese fino fatalismo que es índice de su visión platónica en la que debió seguir latiendo su convicción de la voluntad providencial y de que 
todo acontecimiento histórico es parte de un ciclo más amplio que, como hemos visto, tiene sus propias leyes ajustadas a un tiempo de nacimiento, germinación, florecimiento, decadencia y consumación parcial o total según el tiempo transcurrido y el recorrido de las esferas. ¿Acaso no lo sabían los propios Incas a juzgar por sus oráculos? ¿Y acaso no repercutirían en el septuagenario historiador, en su apacible y solitario retiro de Córdoba, las palabras del Eclesiastés?: “Todo tiene su momento y todo cuanto se hace debajo del sol tiene su tiempo. Hay tiempo de nacer y tiempo de morir, tiempo de plantar y tiempo de arrancar lo plantado; tiempo de matar y tiempo de curar; tiempo de destruir y tiempo de edificar...".

"Como en su propia vida..." pensaría. Esa vida que ya vivía en su obra preñada de luces y sombras, de sabiduría y de nostalgia, de remotas presencias amigas y de gloriosos imperios apagados. Como era su propia existencia consumida por el ansia de inmortalidad y de saber que la orgullosa divisa de los Garcilaso resumía tan bien: "Con la espada y con la pluma”. Divisa que temblaba entre suaves claroscuros a la luz mortecina de unos cirios que se extinguían.

Aquella especulación neoplatónica de tradición hebraica y cabalística en la que los ciclos universales resultaban de la suma del tiempo y el giro de los planetas en las ocho esferas, debe habérsele aparecido como una coincidente y personal alegoría en su escudo de armas. Debe haber pensado, con poderosa visión renacentista, que las sierpes -o amarus-coronadas, entrelazadas por sus colas, y en cuyas fauces reposan los extremos de un arco iris del que pende una mascapaicha o borla -la corona real de los Incas- era la representación de uno de los elementos cíclicos en juego: el tiempo. El tiempo, representado por esas sierpes que son emblema del transcurso en la vida inferior, como el arco iris lo es del mundo superior. Un Tiempo circular, cerrado en 
sí mismo y que abarca en la unión sin solución de continuidad de sus dos niveles, el Universo. Y el otro elemento de la medida del orden cósmico y el cumplimiento de los ciclos: los planetas. En el blasón del Inca están significados por el Sol y la Luna, reguladores del tiempo. Pensaría el cuzqueño que pocas veces el genio humano había logrado revelar tanto de la gran máquina del universo como en el lenguaje admirablemente conciso, claro y universal de los símbolos. Y con secreto orgullo meditaría asimismo en el significado de la mascapaicha, aquel emblema de reyes por sus antepasados maternos que evidenciaba una suprema autoridad: intermediarios entre el mundo de los hombres y el de los dioses. Tal como lo habían sido aquellos emperadores, Hijos del Sol, que usaban esa borla de finos hilos de lana púrpura sobre los ojos, inequívoca señal de pontífices, es decir, puentes entre el Kay Pacha -el mundo de la humanidady el Hanaq Pacha -el mundo de las divinidades-.

Él se reconocería, midiendo cuidadosamente su pensamiento, heredero de esos emblemas y del empuje de casta de ese ilustre linaje. Sentiría por ello el llamado de una misión en la que repercutían analógicos significados: sería el intermediario entre el pasado y el futuro continuándola con la pluma, con la idea, lo que facilitaría la gran continuidad entre un ciclo y otro. No sería el destino magno de una casta que comunicó el mundo de Abajo con el de Arriba, pero sí el que los uniría en el tiempo, como el trazado de una gran línea horizontal sobre la vertical ya cumplida por sus abuelos.

En su mente figuraría esa gran cruz emblemática que daría renovado sentido a sus gloriosos blasones cuzqueños. Era un reto que requería de una vida ascética, retirada, silenciosa. El clérigo de órdenes menores, intermediario de Cristo en su pequeño universo andaluz, se transformó entonces en la voz misma de su linaje, voz de melancólico príncipe quechua en un 
exilio incendiado por el cumplimiento fervoroso, y fatal, de su Obra Mayor.

Creo que el programa implícito en los Comentarios Reales es una de las formas en que uno de nuestros más grandes escritores -no solo historiador- dejó plasmado como un modelo para entender las raíces de la patria naciente, de manera similar al que, trescientos años más tarde, el insigne Ricardo Palma comprendería, o intuiría, al proyectar en el alma y la memoria de sus lectores rasgos principalísimos del carácter peruano, particularmente limeño, a través de un género, la Tradición. En los dos hay un manejo diestro de la licencia literaria que les permite una forma de fijar su aproximación al pasado, que lo rígido de la investigación histórica dificulta. Los dos a su manera crearon una forma intransferible de escribir, y lo dos lo hicieron fascinados por las personalidades y los acontecimientos de una época ya ida pero que sabían actuante en las profundidades del alma colectiva.

Es así que mi recorrido con rumbo a Palma pretende pasar por algunas de las cimas peruanas de este singular tratamiento de la literatura y la historia que hunden sus raíces en los días aurorales de la Conquista, transcurre a través de medio milenio y actualmente retorna con renovados bríos. 